\title{
GERAKAN SOSIAL RUMAH SEHAT DAN IMUNISASI BCG SEBAGAI LANGKAH MENURUNKAN KEJADIAN TUBERKULOSIS \\ (TB) ANAK
}

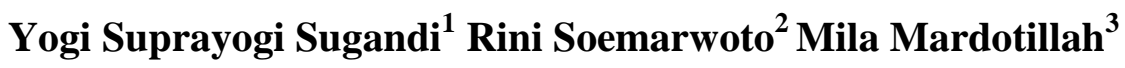 \\ Fakultas Ilmu Sosial dan Ilmu Politik Universitas Padjadjaran, Indonesia \\ Email: jayasuwirta@gmail.com
}

\begin{abstract}
In an effort preventive and promotion to improve health degree, individuals and families must understand the concept of sick and healthy. Understanding of the concept can help everyone in maintaining their health with the help of medical and social surroundings. Social assistance is an environment which a child grows and develops. Social support in creating a healthy home conditions and the implementation of BCG immunization is necessary condition of the child in an effort to prevent child's TB disease. Child's life would be a lot of spent time at home, so parents need to understand how healthy housing conditions as well as the support of family health also immunization status that must be met by parents for a child's rights in obtaining proper health status. Healthy homes and BCG immunization is an effort to reduce the number of child's TB. The role and knowledge of parents to the importance of these two things is major key to the success of child's TB treatment in terms of preventive and health promotion role very valuable in enhancing parents knowledgeable on child TB incidence. Support for social groups that formed in the communities through the role of cadres, religious figures, community figures and officials is important things for the successful of children tuberculosis treatment through healthy housing conditions and BCG immunization.
\end{abstract}

Keywords : Home Conditio;BCG immunization; Child TB; Support for social groups

\section{Pendahuluan}

Penyakit berbasis lingkungan yang masih mencapai angka tinggi setiap tahunnya adalah penyakit Tuberkulosis $(T B)$ yang disebabkan oleh bakteri Micobacterium tuberculosis dan merupakan masalah kesehatan masyarakat yang penting di Indonesia. Penyakit TB merupakan penyakit berbasis lingkungan dengan tingkat penyebaran tinggi melalui droplet di udara dan dapat menyebar cepat terutama bila di dukung oleh lingkungan dan kondisi rumah yang tidak sehat. Penyakit TB anak berasal dari kuman TB yang menyerang orang dewasa, namun penegakan diagnosis TB pada anak berbeda dengan penegakan diagnosis TB pada orang dewasa. Diagnosis TB dapat ditegakkan berdasarkan gejala klinis, pemeriksaan fisik dan anamnesis dokter sangat menentukan dalam menegakan TB pada anak. Pada tahun 1992, WHO telah mencanangkan TB sebagai global emergency. Pada tahun 2010 dilaporan insidens TB di dunia sebesar 8,8 juta $(8,5$ 9,2 juta). Tahun 2009 dilaporkan terjadi 2,4 kasus baru (3,3 juta perempuan). $80 \%$ kasus TB aktif ditemukan di 22 negara 
berkembang sebagian besar di Asia (55\%) dan Afrika (30\%). Sekitar $5 \%$ dari beban kasus TB global sekarang resisten terhadap beberapa obat. (PPTI, 2012).

Rumah Sehat merupakan penilaian terhadap proporsi rumah yang memenuhi kriteria sehat minimum komponen rumah dan sarana sanitasi dari tiga komponen (rumah, sarana sanitasi dan perilaku) di satu wilayah kerja pada kurun waktu tertentu (Depkes RI,2007). Komponen dalam rumah sehat merupakan sarana tidak langsung terhadap keterpaparan suatu penyakit dikarenakan rumah berfungsi sebagai tempat hidup dan bernaung manusia.

Imunisasi adalah suatu upaya untuk menimbulkan atau meningkatkan kekebalan seseorang secara aktif terhadap suatu penyakit, sehingga apabila suatu saat terpajan dengan penyakit tersebut tidak akan sakit atau hanya mengalami sakit ringan. (Kemenkes RI, 2015). Imunisasi pencegahan terhadap penyakit TB adalah dengan imunisasi BCG dan termasuk ke dalam salah satu imunisasi wajib yang harus diterima oleh bayi sebelum usia 3 bulan. Dalam menegakan diagnosis penyakit $\mathrm{TB}$, status imunisasi sangat berpengaruh kepada pengobatan selanjutnya. Bila anak tersebut belum pernah mendapat imunisasi BCG, imunisasi BCG dilakukan setelah pengobatan pencegahan selesai (Depkes RI, 2006).

Berdasarkan data WHO tahun 2014, kasus TB di Indonesia sebesar $127 / 100.000$ populasi dari seluruh populasi penduduk dan sebanyak 23.170 orang adalah penderita TB usia 0-15 tahun dengan komposisi anak 0-4 tahun sebesar 85/100.000 populasi dan anak 5-14 tahun sebesar 54/100.000 populasi. Data profil Kesehatan Kota Bandung terdapat 1.536 kasus TB anak atau sebesar $21.68 \%$ dari seluruh kasus TB. Dari kasus tersebut hanya $15 \%$ yang terjaring oleh puskesmas dan sisanya berasal dari fasilitas pelayanan kesehatan lainnya. Masyarakat belum sepenuhnya memanfaatkan puskesmas dalam mengatasi masalah TB anak, hal ini merupakan tantangan bagi puskesmas dalam hal ini sebagai sarana pelayanan kesehatan dasar dalam meningkatkan program TB anak.

Cakupan imunisasi BCG dan peningkatan rumah sehat memerlukan dukungan kelompok sosial sebagai upaya meningkatan kesadaran masyarakat akan pentingnya rumah sehat dan imunisasi 
BCG dan bahayanya penyakit TB pada anak. Dukungan kelompok sosial secara terus menerus dapat membantu masyarakat lebih mandiri dan paham tentang pentingnya pencegahan TB pada anak.

\section{Metode Penelitian}

Metode penelitian bersifat deskriptif kuantitatif memakai desain potong lintang (cross sectional) dengan mengambil kasus di Kecamatan Mandalajati Kota Bandung. Alasan pengambilan tempat yaitu Kecamatan Mandalajati merupakan kecamatan pemekaran kecamatan sejak tahun 2008 juga merupakan wilayah pemekaran dari Kabupaten Bandung menjadi Kota Bandung sehingga pola masyarakat lebih beragam baik sebagai masyarakat urban maupun masih terdapat pola masyarakat pedesaan.

Populasi dan sampel adalah seluruh anak balita dan rumah di wilayah kerja UPT Puskesmas Sindangjaya dengan pengambilan data di bulan Maret 2016 terhadap seluruh sampel yang diteliti. Selain itu, dilakukan pula wawancara kepada para tokoh terkait diantaranya petugas teknis, LPM sebagai tokoh masyarakat dan kader kesehatan.

\section{Hasil dan Pembahasan}

Setiap warga negara berhak memperoleh derajat kesehatan setinggi-tingginya dan hidup dalam kondisi kesehatan optimal. Derajat kesehatan dipengaruhi oleh 4 faktor yaitu lingkungan, perilaku, pelayanan kesehatan dan genetik (Blum, 1974). Lingkungan dan perilaku saling terkait dalam penanganan kasus TB anak.

Kesalahan mendiagnosis penyakit TB terutama pada anak menjadikan salah satu faktor terjadinya resistensi obat TB yang ada, selain ketidakdisiplinan dalam mengkonsumsi obat TB. Dalam memahami penegakan diagnosis, individu maupun keluarga harus mengetahui dasardasar penegakan diagnosis TB dengan memakai skoring dari Ikatan Dokter Anak Indonesia (IDAI). Penengakkan diagnosis perlu disampaikan oleh dokter sampai orang tua atau keluarga, selain itu kelompok sosial di masyarakat dapat diwakili oleh PKK atau kader kesehatan, Kelurahan, Kecamatan, puskesmas perlu berperan aktif dan mengetahui batasanbatasan diagnosis TB secara umum agar kelompok sosial tersebut dapat membatu keluarga dalam memahami dan melaksanakan pengobatan TB anak sesuai dengan prosedur yang berlaku. Adapun penetapan skoring TB anak berdasarkan 
Standar Ikatan Dokter Anak Indonesia

(IDAI) dapat dilihat pada gambar 1 .

Gambar 1 : Skoring penegakan diagnosis TB pada anak

\begin{tabular}{|c|c|c|c|c|c|}
\hline Parameter & $\mathbf{0}$ & 1 & 2 & 3 & Skor \\
\hline Kontak TB & $\begin{array}{l}\text { Tidak } \\
\text { jelas }\end{array}$ & - & $\begin{array}{c}\text { Laporan } \\
\text { keluarga, } \\
\text { BTA (-) / BTA } \\
\text { tidak } \\
\text { jelas/ tidak } \\
\text { tahu }\end{array}$ & BTA (+) & \\
\hline $\begin{array}{l}\text { Uji tuberkulin } \\
\text { (Mantoux) }\end{array}$ & Negatif & - & - & $\begin{array}{c}\text { Positif ( } \geq 10 \mathrm{~mm} \\
\text { atau } \geq 5 \mathrm{~mm} \text { pada } \\
\text { imunokompromais) }\end{array}$ & \\
\hline $\begin{array}{l}\text { Berat Badan/ } \\
\text { Keadaan Gizi }\end{array}$ & - & $\begin{array}{c}\mathrm{BB} / \mathrm{TB}<90 \% \text { atau } \\
\mathrm{BB} / \mathrm{U}<80 \%\end{array}$ & $\begin{array}{c}\text { Klinis gizi buruk } \\
\text { atau BB/ } \\
\text { TB }<70 \% \\
\text { atau } \mathrm{BB} / \\
\mathrm{U}<60 \%\end{array}$ & - & \\
\hline $\begin{array}{l}\text { Demam yang } \\
\text { tidak diketahui } \\
\text { penyebabnya }\end{array}$ & - & $\geq 2$ minggu & - & - & \\
\hline Batuk kronik & - & $\geq 3$ minggu & - & - & \\
\hline $\begin{array}{l}\text { P e m b e s a r a n } \\
\text { kelenjar } \\
\text { limfe kolli, aksila, } \\
\text { inguinal }\end{array}$ & - & $\begin{array}{c}\geq 1 \mathrm{~cm} \text {, lebih dari } 1 \\
\text { KGB, tidak nyeri }\end{array}$ & - & - & \\
\hline $\begin{array}{l}\text { Pembengkakan } \\
\text { t u I a ng/s e n d i } \\
\text { panggul, } \\
\text { lutut, falang }\end{array}$ & - & Ada pembengkakan & - & - & \\
\hline Foto toraks & $\begin{array}{l}\text { Normal/ } \\
\text { kelainan } \\
\text { tidak jelas }\end{array}$ & $\begin{array}{l}\text { Gambaran sugestif } \\
\text { (mendukung) TB }\end{array}$ & - & - & \\
\hline \multicolumn{5}{|c|}{ Skor Total (maksimal 13) } & \\
\hline
\end{tabular}

Sumber : IDAI DIY

Imunisasi merupakan sebuah langkah awal dalam menghindarkan anak dari penyakit TB. Vaksin BCG diberikan satu kali pada usia 1 bulan guna mencegah kuman tuberkulosis menyerang paru, dan selaput radang otak yang bisa menimbulkan kematian atau kecacatan. (www.depkes.go.id) Selain tindakan pemberian vaksin, setiap sarana kesehatan wajib memperhatikan kualitas vaksin yang akan diberikan dan selalu memperhatian standar prosedur operasional agar vaksin yang diberikan efektif. 
Masalah kesehatan akan lebih banyak didapatkan pada golongan rentan, salah satunya bayi dan balita. Isu global WHO tentang risiko kesehatan lingkungan anak-anak adalah meningkatkan kualitas kesehatan lingkungan anak-anak salah satunya adalah peningkatan kondisi rumah agar sehat. Pencemaran dapat terjadi di dalam dan luar lingkungan rumah. Anakanak banyak menghabiskan waktu di dalam rumah dan lingkungan sekitarnya baik rumah sendiri, penitipan anak, rumah pengasuh yang dibayar, preschool dan taman kanak-kanak. Penelitian yang dilakukan oleh Tso dan Yeung tahun 1996, Farrow tahun 1997, anak-anak menghabiskan $80 \%$ atau lebih kehidupan mereka di dalam rumah melebihi orang dewasa ketika mereka masih sangat muda, oleh karena itu, di dalam rumah, anakanak dapat tertimpa mayoritas pajanan dan infeksi yang lebih besar (WHO, 2005).
Dalam meningkatkan kualitas kondisi rumah, terdapat pedoman yang dapat dipahami orang tua dalam menciptakan kondisi rumah sehat. Pedoman teknis penilaian rumah sehat disusun berdasarkan Kepmenkes RI No. 829/Menkes/SK/VII/1999 tentang Persyaratan Kesehatan Perumahan dan merupakan penyempurnaan dari (empat belas) variabel rumah sehat yang telah dikembangkan dalam Susenas dengan menambahkan penilaian pada aspek perilaku penghuni rumah.

Kondisi rumah sehat dan status imunisasi anak memegang peranan pada angka kejadian TB. Data imunisasi BCG di Kota Bandung pada tahun 2014 sebanyak 99,93\% anak mendapatkan imunisasi BCG dan sebanyak 73,75\% kondisi rumah penduduk di Kota Bandung termasuk pada kategori baik. Data status imunisasi, kondisi rumah dan angka kejadian TB terdapat dalam tabel 1.

Tabel 1 : Data status imunisasi BCG, Kondisi Rumah dan Kejadian TB Anak di Kota Bandung Tahun 2014

\begin{tabular}{cccc}
\hline Variabel & Tertinggi & Terendah & Total Kota Bandung \\
\hline Imunisasi BCG & Cinambo (114\%) & $\begin{array}{c}\text { Tamblong } \\
(91.40 \%)\end{array}$ \\
\hline Kondisi Rumah & $\begin{array}{c}\text { Griya Antapani } \\
(90.23 \%)\end{array}$ & $\begin{array}{c}\text { Citarip } \\
(61.84 \%)\end{array}$ \\
\hline $\begin{array}{c}\text { Kejadian TB } \\
\text { anak }\end{array}$ & $\begin{array}{c}\text { Riung Bandung } \\
(38.89 \%)\end{array}$ & $\begin{array}{c}\text { Panghegar } \\
(0 \%)\end{array}$ & $73.75 \%$ \\
\hline & Sumber : Profil Kesehatan Kota Bandung Tahun 2014
\end{tabular}


Dari data tersebut, peran aktif puskesmas sebagai ujung tombak pelayanan kesehatan masyarakat perlu ditingkatkan mengingat masyarakat lebih memilih pelayanan kesehatan ke jenjang yang lebih tinggi dalam mengatasi masalah TB pada anak, selain itu masih perlunya keterjangkauan masyarakat dalam mendapatkan pembinaan bagi kondisi rumah dan status imunisasi melalui gerakan sosial masyarakat.

Data rumah sakit menunjukan bahwa temuan TB lebih besar daripada data lapangan dalam hal ini Puskesmas, hal ini dapat disebabkan oleh beberapa faktor yaitu sulitnya penegakan diagnosis TB pada anak dan harus berdasarkan hasil skoring yang ditetapkan oleh dokter. Ketersediaan sarana alat tes uji tuberculin dan foto rontgen tidak tersedia di puskesmas sehingga penegakan diagnosis harus dilakukan di RS, selain itu TB anak tidak ditularkan melalui anak tetapi dari orang dewasa dengan BTA positif. Penegakan BTA positif melalui uji dahak yang dapat dilakukan di puskesmas, namun kendala alat dan keengganan masyarakat untuk memeriksakan diri menjadikan temuan kasus belum memenuhi target.
Berdasarkan data bulan Maret 2016 dengan mengambil satu kasus di Wilayah Kerja UPT Puskesmas Sindangjaya Kecamatan Mandalajati bahwa dari jumlah 157 bayi $0-5$ bulan baru sebanyak 60 bayi mendapatkan imunisasi BCG atau sebesar $38,22 \%$. Kondisi rumah sudah $96 \%$ dengan kategori rumah sehat, sedangkan angka kejadian TB anak 1 orang dari 2043 balita atau sebesar $0,04 \%$.

Dari data tersebut bahwa temuan TB anak sangat sulit di lapangan. Masyarakat masih merasa malu dan tidak siap bila sudah didiagnosis TB sehingga penanganan TB yang terjadi sudah pada tahap lanjutan selain pengetahuan orang tua dalam memahami ciri-ciri TB pada anak. Angka temuan TB anak dapat pula disebabkan belum terjaringnya anak yang sudah diberikan pengobatan TB oleh RS. Bila dilihat dari peran serta masyarakat dalam melakukan imunisasi BCG, maka angka BCG masih rendah dibandingan dengan jumlah bayi usia 0-5 bulan. BCG seharusnya paling lambat diberikan pada anak sampai usia 3 bulan. Sedangkan data rumah sudah menunjukan hasil yang baik tetapi masih perlu dilakukan pemeriksaan lebih lanjut pada sarana ventilasi dan pencahayaan rumah secara lebih detail. 
Berdasarkan kasus diatas bahwa peningkatan peran orang tua dalam pemberian imunisasi BCG pada anak diperlukan dukungan kelompok sosial. Dukungan sosial dapat pula diberikan pada orang tua bila ditemukan anak dengan ciriciri yang mengarah kepada TB Anak sesuai panduan IDAI. Pengamatan pada lokasi penelitian bahwa masyarakat yang terbagi dalam beberapa kelompok dasawisma. Dasawisma dalam satu RT memiliki kader aktif yang berperan sebagai early warning pada setiap kasus TB Anak. Kader berperan aktif memantau status imunisasi bayi dalam setiap posyandu dan menjadi mitra terbaik bagi petugas puskesmas dalam melakukan kunjungan rumah memeriksa kondisi kesehatan rumah. Kelompok sosial melalui Posyandu, PKK dan dasawisma dapat memberikan bantuan saran dan dukungan pada orang tua atau masyarakat agar melakukan pengobatan sesuai prosedur apabila ditemukan anak dengan ciri-ciri mengarah kepada TB.

Keberhasilan upaya preventif dalam menangani kasus TB anak haruslah mempertimbangkan aspek sosial karena anak hidup dalam lingkungan sosial. Setiap individu berpikir dan bertingkah laku dihadapkan pada gejala-gejala atau fakta-fakta sosial. Fakta-fakta sosial itu merupakan entitas yang berdiri sendiri lepas dari fakta-fakta individu yang memaksa individu bertindak dan berpikir menurut garis-garis dan bertindak menurut cara-cara tertentu. (Koentjaraningrat, 1987:88). Fakta sosial merupakan langkah awal untuk melihat gejala yang akan di observasi. (Durkheim dalam Lapau, 2015: 9). Bila dikaitkan dengan program kesehatan, maka promosi kesehatan harus menjadi gagasan kolektif, sejalan dengan pemikiran Durkheim bahwa suatu gagasan kolektif sudah dianggap berada diluar diri para individu dan mendapat formasi. Gagasan kolektif dianggap berada diatas para individu karena mempunyai kekuatan untuk mengatur perilaku dan menjadi pedoman bagi kehidupan warga masyarakat. Pengamatan di Wilayah Kerja UPT Puskesmas Sindangjaya, bahwa promosi kesehatan berfungsi sebagai motor penggerak dan menjadi acuan setiap warga dalam mencegah kejadian TB Anak. Kebutuhan masyarakat akan pentingnya fisik dan mental anak mendorong setiap orang berpatisipasi baik sebagai kader maupun pengurus RT dan RW.

Masyarakat dalam mendiagnosis keadaan kesehatannya berdasaran pada gejala dan tanda yang dirasakan, proses sakit dan penyebabnya. Latar belakang 
budaya dan pengalaman pribadi mempengaruhi cara pandang dan tindakan seseorang dalam menghadapi sakitnya. Tanpa gejala, sebuah penyakit akan sulit di tegakkan diagnosisnya (Imelda, 2014:6). Peran pemerintah melalui tenaga kesehatan dan aparat kewilayahan mendampingi masyarakat diwakili oleh kader tiap RT dan RW. Petugas memberikan pengetahuan melalui pertemuan bulanan baik di Puskesmas, Kelurahan dan Posyandu. Tindakan pemberian imunisasi dan kunjungan rumah dapat pula dilakukan pada saat posyandu.

Keadaan penyakit ditinjau dari aspek sosial seperti aspek-aspek fisik, mental dan medis menunjukkan suatu urutan waktu. Ada suatu awal yakni kesadaran akan gejala-gejala awal yang samar, ada suatu perkembangan, yaitu proses sosial dan proses fisiologis yang terjadi dan ada suatu akhir melalui kesembuhan atau kematian. Selama proses ini, keputusan-keputusan medis dan sosial harus dilakukan, peranan-peranan disesuaikan kembali dan sikap-sikap diubah untuk disesuaikan dengan keadaan. (Foster, 2013:172). Tingkah laku sakit, peranan sakit dan peranan pasien sangat dipengaruhi oleh faktor-faktor seperti kelas sosial, perbedaan suku bangsa dan budaya. (Foster, 2013:173). Dengan kasus kesehatan yang sama, reaksi individu akan berbeda tergantung dari faktor-faktor dominannya. Pengamatan di lokasi penelitian, bahwa setiap keluarga yang mendapatkan kasus anak dengan TB memiliki status tidak di imunisasi BCG dengan kondisi ventilasi dan pencahayaan rumah yang kurang. Namun ada pula kasus dengan imunisasi yang terlambat dan tertular dari anggota keluarga dewasa yang terkena TB, selain itu luas rumah yang tidak memadai menjadi pemicu terjadinya kasus TB anak.

Kemampuan merubah harus dapat diawali dengan mengidentifikasi setiap perilaku individu mengenai tujuan dan kerangka logis dari setiap perilaku yang dihasilkan seseorang tanpa menilai terlebih dahulu atau fungsi apa yag sedang dijalani dari perilaku tersebut sehingga menghasilkan konsekuensi-konsekuensi perilaku seseorang (Barth, 1981:2). Setelah memahami latar belakang dan tingkat pemahaman individu dalam berperilaku, maka intervensi dapat dilakukan dengan baik. Kekuatan yang dapat memengaruhi perubahan perilaku mulai dari adanya intervensi yang 
berproses dan memahami struktur yang ada dan merekonstruksinya sesuai dengan tujuan promosi kesehatan tersebut (Burawoy, 1998:22). Hal pertama yang dapat dilakukan adalah peningkatan kunjungan bayi. Dalam kunjungan bayi, status imunisasi BCG menjadi salah satu hak yang harus diterima bayi, selain itu selama melakukan kunjungan, petugas dapat memberikan masukan terhadap kondisi rumah tempat bayi tersebut.

Individu akan lebih sulit memodifikasi atau merubah tingkah lakunya apabila melakukan serupa dengan tingkah laku baru adalah apabila didekati secara individual, kecenderungan perubahan terjadi manakala didekati sebagai anggota suatu kelompok. Dengan demikian, modifikasi tingkah laku yang individual tersebut berlangsung bersamasama dengan perubahan dalam suasana kelompok. Seseorang membutuhkan kesepakatan dari kelompoknya, karena itu akan menyesuaikan tingkah lakunya kepada ukuran kelompoknya, dengan demikian akan mudah pula berubah jika kelompoknya berubah (Garna, 2002:83). Kenyataan sosial objektif ini kemudian dihadapkan pada individu, bersifat memengaruhi dan memaksa pembentukan pola pikir, sikap, tindakan, dan perilaku individu-individu. (Widiastuti, 2012 : 166). Hal ini merupakan sebuah dasar bagi promosi kesehatan dalam mendekati masyarakat guna meningkatkan kondisi rumah dan meningkatkan cakupan imunisasi BCG dengan dilakukannya pendekatan secara aktif oleh tokoh masyarakat, tokoh agama dan pemerintahan setempat yang bergerak bersama-sama demi memberikan dukungan pada masyarakat.

Sebuah kelompok sosial merupakan agen dalam mendukung kepada perubahan sosial suatu komunitas. Perubahan berjalan berdasarkan proses didukung oleh struktur yang menaunginya. Proses dalam makna sosial pada hakekatnya ialah perjalanan kehidupan suatu masyarakat dalam menghadapi situasi sosialnya (Garna,2002:5).

Gerakan sosial yang dilakukan oleh kader sebagai agen, bekerja pada struktur organisasi kemasyarakatan setempat secara terus menerus. Kader dalam melaksanakan tugasnya mendapatan dukungan dari pemerintah setempat maupun warga masyarakatnya. Kader sebagai pembina dan agen perubahan di masyarakat sangat berpengaruh kepada peningkatan dan ketertarikan masyarakat terhadap pelaksanaan pencegahan TB anak. Kader 
merupakan agen yang mampu menyampaikan promosi kesehatan pada masyarakat agar pengetahuan dan perilaku masyarakat dapat meningkat. Perubahan sosial yang diharapkan yaitu sebuah perkembangan yang merupakan perubahan tertuju kepada kemajuan keadaan dan hidup anggota masyarakat, sehingga akan dinikmati pula oleh individu. (Garna,2002:7). Lingkungan sehat dan terbebas dari kuman TB merupakan kemajuan yang diharapkan masyarakat. Temuan yang didapat dari pengamatan, wawancara dan observasi pada Wilayah Kerja UPT Puskesmas Sindangjaya bahwa kasus TB anak terjadi karena lolosnya imunisasi BCG yang disebabkan penolakan orang tua terhadap imunisasi dan kondisi bayi yang kurang sehat, sedangkan kondisi rumah dengan kasus TB anak memiliki ventilasi, pencahayaan dan luas wilayah kurang dibandingkan dengan jumlah penghuni. Namun hal ini dapat diatasi bila cakupan imunisasi BCG terus ditingkatkan baik dengan kunjungan rumah bayi ataupun posyandu dan perbaikan kondisi rumah sesuai kemampuan warga.

Pencegahan TB anak berarti pula pencegahan TB dewasa karena TB anak berasal dari kuman TB dewasa. Kesadaran tersebut dapat dibangun bila ada dukungan dari kelompok sosialnya. Pencegahan TB anak terkait pada sejauh mana perubahan sosial dari masyakarat terjadi agar kejadian TB dapat ditekan sekecil mungkin. Kesadaran pencegahan tidak terlepas dari perubahan sosial yang sudah terjadi, bukan hanya menjadi tanggung jawab individu tetapi masyarakat sekelilingnya. Perubahan sosial tidak berdiri sendiri tetapi saling keterkaitan antara bagian-bagian dalam masyarakat sebagai suatu sistem itu dapat memberikan arti, bahwa perubahan pada satu bagian akan mempunyai implikasi yang penting pada bagian-bagian lain dalam masyarakat. (Garna, 2002:59). Perubahan sosial tidak terjadi bila kesadaran hanya timbul dari individu tetapi harus timbul juga dari masyarakat sekelilingnya juga dukungan pemerintah setempat. Pendampingan pemerintah pada masyarakat setempat baik kader maupun RW sangat diperlukan agar masyarakat menjadi Pemahaman tentang penyakit TB dan upaya pencegahannya melalui rumah sehat dan imunisasi harus dipahami bersama dalam kelompok masyarakat. Gerakan sosial memberantas TB sangat efektif dilakukan agar orang tua dan masyarakat dapat berperan aktif 
menangani secara mandiri melalui usaha preventif dan promotif melalui kelompok sosial yang dilakukan di setiap RW bersama-sama dengan dukungan pemerintah setempat.

\section{Simpulan}

Kasus TB anak di Wilayah Kerja Puskesmas Sindangjaya pada Triwulan I tahun 2016 adalah 0,04 \%, cakupan imunisasi $\mathrm{BCG} 38,22 \%$, namun kondisi rumah penduduknya sudah mencapai $96 \%$. Dalam meningkatkan cakupan imunisasi BCG, kunjungan rumah bayi oleh petugas dan peran serta ibu bayi dalam membawa anaknya ke puskesmas dan posyandu sangat diperlukan. Tema imunisasi BCG dan rumah sehat disisipkan dalam kunjungan rumah kasus TB dewasa. Penyuluhan tentang imunisasi, rumah sehat dan penyakit TB baik di puskesmas, kelurahan dan posyandu harus terus dilakukan agar masyarakat semakin sadar pentingnya imunisasi $\mathrm{BCG}$ dan perbaikan kondisi rumah dalam menekan kasus TB anak.

Pencegahan kasus TB anak melalui imunisasi dan perbaikan kondisi rumah sudah efektif digunakan di Wilayah Kerja UPT Puskesmas Sindangjaya, namun hal ini harus terus dipelihara keberlanjutannya melalui kerjasama dan peran serta petugas pemerintah bersama kader dan pengurus kewilayahan.

Upaya preventif dan promotif merupakan sebuah tindakan dalam mencegah meningkatnya angka kejadian suatu penyakit. Upaya preventif kejadian TB anak dapat dilakukan mulai dari rumah tangga yaitu orang tua balita dengan meningatkan kondisi rumah sehat dan melakukan imunisasi BCG, orang tua berperan aktif mencari informasi pada pembina wilayah setempat dengan dukungan tokoh masyarakat dan tokoh agama setempat dan pemerintah dalam hal ini institusi kesehatan juga aparat baik tingkat kewilayahan, Kota/Kabupaten, Provinsi maupun Pusat. Keberhasilan upaya preventif penanganan TB anak dengan meningkatkan kondisi rumah dan cakupan imunisasi BCG sangat ditentukan oleh kelompok sosial yang mendukungnya. Gerakan sosial secara menyeluruh melalui kegiatan posyandu, rapat-rapat RW dan kegiatan kemasyarakatan lainnya secara terus menerus melalui promosi kesehatan akan mendukung upaya preventif penanganan TB anak. 


\section{Daftar Pustaka}

Barnard A. 2004. History and Theory in Anthropology. UK : The Press Syndicate

Barth F. 1981. Features of person and society in Swat Collected essays of Pathans. London : Routledge\&egan Paul Ltd.

Blum, H. 1974. Planning For Health, Development and Application of Social Change Theory. New York: Human Science Press.

Bordieu, P. 1990. The Logic of Practice. California: Atanford University Press.

Burawoy M., The Extended Case Method. Jurnal Sociological Theory 16:1 March 1998. American Sociological Association.

Departemen Kesehatan RI. 2006. Pedoman Nasional Penanggulangan Tuberkulosis. Jakarta : Dirjen P2PL Depkes RI.

Departemen Kesehatan RI. 2007. Pedoman Teknis Penilaian Rumah Sehat. Jakarta : Dirjen P2PL Depkes RI.

Dinas Kesehatan Kota Bandung. Profil Kesehatan tahun 2014.

Eckholm, Erik P. 1982. Lingkungan Sebagai Sumber Penyakit. Jakarta : PT Gramedia
Foster. GM., Anderson BG. 2013. Atropologi Kesehatan. Jakarta : UI Press

Garna, Judistira K. 2002. Teori-teori Perubahan Sosial. Bandung : CV Primaco Akademika

Gordon B, Mackay R, Rehfuess E. Inhereting the world:The atlas of children's health and the environment. UK : Myriad Editions Limited; 2004 Tersedia dari : http://www.who.int/ [11 September 2009].

Ihromi TO. 1996. Pokok-pokok Antropologi Budaya. Jakarta : Yayasan Obor Indonesia

Ikatan Dokter Anak Indonesia (IDAI). Skoring TB pada Anak 2015. Tersedia http://www.idaijogja.or.id/skorin

g-tb-pada-anak/ [05/01/2016] 2.

Imelda JD. 2014. Disease interpretations and Response among $\mathrm{HIV}$ positive Mothers. Jurnal Antropologi Indonesia Vo. 35 No. 1 Tahun 2014.

Keputusan Menteri Kesehatan Republik Indonesia Nomor 829/Menkes/SK/VII/1999 tentang Persyaratan Kesehatan Perumahan.

Kementerian Kesehatan RI. 2015. Buku Ajar Imunisasi. Jakarta : Pusdiknakes RI.

Koentjaraningrat. 1990. Kebudayaan Mentalitas dan Pembangunan. 
Jakarta : PT Gramedia Pustaka Utama

Koentjaraningrat. 1987. Sejarah Teori Antropologi I. Jakarta : UI Press

Koentjaraningrat. 1987. Sejarah Teori Antropologi II. Jakarta : UI Press

Lapau B, Saiffudin AF. 2015. Epidemiologi dan Antropologi. Jakarta : Prenadamedia Grup.

Nasikun. 1995. Sistem Sosial Indonesia. Jakarta : PT Raya Grafindo Persada

Notoatmodjo, S. (2005). Promosi Kesehatan, Teori dan Aplikasi. Jakarta: Rineka Cipta.

Singer, Merryl. The Anthropology of Infectious Disease. 2015. USA : Left Coast Press, Inc

Susilo, Rachmad KD. 2005. Integrasi Ilmu Sosial. Upaya Integrasi Ilmu Sosial Tiga Peradaban. Yogyakarta : Arruz Media

Undang-undang Kesehatan Republik Indonesia No. 36 tahun 2009 tentang Kesehatan

UNICEF. 2012. Air bersih, Sanitasi dan Kebersihan. Jakarta : UNICEF Indonesia

Widiastuti T. 2012. Strategi Pesan Promosi Kesehatan Cegah Flu Burung. Jurnal MIMBAR Vol. 28 No. 2 Tahun 2012.
Van Ufford, Philip Q. Frans Husken, et all. Alih Bahasa : RG Soekadijo. 1989. Tendensi dan Tradisi dalam Sosiologi Pembangunan. Jakarta : PT Gramedia

Van Baal. Sejarah dan Pertumbuhan Teori Antropologi Budaya. 1988. Jakarta : PT. Gramedia.

Veeger KJ. 1993. Realitas Sosial. Jakarta : PT Gramedia

Wijaya AA. Merokok dan Tuberkulosis. 2012. Jurnal Tuberkulosis Indonesia Vol 8-Maret 2012

World Health Organization. Children's Environmental Health Programme.2009 Tersedia dari http://www.who.int/ceh[23 Agustus 2009].

World Health Organization. Indikator perbaikan kesehatan lingkungan anak. Alih bahasa : Apriningsih. Editor : Herdiyanti EA. Jakarta: EGC;2005.

World Health Organization. Global

Tuberculosis Report 2015.

Tersedia :

http://www.who.int/tb/publication s/global_report/gtbr15_annex04.p df?ua $=1[12 / 01 / 2016] 2.575 .478$ $107 /$ 